\title{
Analytical study and evaluation results of power optimizers for distributed power conditioning in photovoltaic arrays
}

\author{
Ricardo Orduz ${ }^{1 *}$, Jorge Solórzano ${ }^{1}$, Miguel Ángel Egido ${ }^{1}$ and Eduardo Román ${ }^{2}$ \\ 1 Instituto de Energía Solar, Universidad Politécnica de Madrid, Avenida Complutense, 28040 Madrid, Spain \\ 2 Fundación Tecnalia Research and Innovation, Energy Unit, Edif. 700 Derio 48160, Spain
}

\begin{abstract}
The use of modular or 'micro' maximum power point tracking (MPPT) converters at module level in series association, commercially known as "power optimizers", allows the individual adaptation of each panel to the load, solving part of the problems related to partial shadows and different tilt and/or orientation angles of the photovoltaic (PV) modules. This is particularly relevant in building integrated PV systems. This paper presents useful behavioural analytical studies of cascade MPPT converters and evaluation test results of a prototype developed under a Spanish national research project. On the one hand, this work focuses on the development of new useful expressions which can be used to identify the behaviour of individual MPPT converters applied to each module and connected in series, in a typical grid-connected PV system. On the other hand, a novel characterization method of MPPT converters is developed, and experimental results of the prototype are obtained: when individual partial shading is applied, and they are connected in a typical grid connected PV array. Copyright $\odot 2011$ John Wiley \& Sons, Ltd.
\end{abstract}

KEYWORDS

MPPT; DC-DC converters; power optimizers; mismatch; shading; different tilt and orientation; BIPV

* Correspondence

Ricardo Orduz, Instituto de Energía Solar, Universidad Politécnica de Madrid, Avenida Complutense, 28040 Madrid, Spain

E-mail: ricardo.orduz@ies-def.upm.es

Received 31 March 2011; Revised 30 June 2011; Accepted 15 August 2011

\section{INTRODUCTION}

The performance of photovoltaic (PV) arrays is inextricably linked to the electrical decoupling between the interconnected PV modules. This can be produced by mismatch effects and/ or environmental factors: different irradiance, temperature, and dirt or shadows casted by nearby objects. Whereas the mismatch effects can be minimised by selecting PV modules with the narrowest dispersion, in the case of building integrated photovoltaic (BIPV) systems, the environmental factors can be very significant. These factors produce a current decoupling in series interconnected strings, which affect the $\mathrm{I}-\mathrm{V}$ curve of the whole PV system and thus, the maximum power tracking efficiency of inverters [1], increasing the power losses.

Modular or 'micro' maximum power point tracking (MPPT) converters, commercially known as "power optimizers", applied to each module allow, on the one hand, the individual adaptation of each panel to the load, solving part of the problems related to partial shadows, minimising dirtiness or ageing mismatching, making it possible to connect PV modules with different characteristics, and reducing risks in installation and maintenance resulting from high DC voltage values. On the other hand, the behaviour of each module can be tested dynamically by means of communications included into the electronic device, through the use of a power line carrier (PLC) signal incorporated into the power signal, which is injected into the grid, facilitating the operation and maintenance of PV arrays. This is especially useful when a large number of PV modules are installed because in this situation, tedious procedures are required to identify whether a PV module is working well. To identify the PV string with problems is normally easy, but it is not so with the exact PV module(s) responsible. This is particularly serious in BIPV systems, where the access to PV modules can be very complex.

Since the early 1990s, research has focused on the incorporation of a low-power electronic device for each PV module called AC modules [2,3]. The technological basis addresses the development of a low-power DC-AC 
converter, with the MPPT algorithm included. This way, the grid connection of the PV modules is carried out directly in alternating current, with no intermediate elements. In this paper, another option is considered: the use of DC-DC converters with an MPPT algorithm, connecting the PV modules in direct current. These options represent what is called distributed or modular architecture, and they offer some advantages over traditional technologies, resulting in a better performance of PV systems in the presence of specific irregular situations.

A great interest in the development of $\mathrm{AC}$ modules arose from its beginnings, in 1992 [4]. This interest has been the focus of German teams [5,6] (ISET University of Kassel), Dutch teams [2] (ECOFYS, Mastervolt), and Japanese teams [7]. A European-funded project, PVMIPS [8], has aimed at developing a commercial $\mathrm{AC}$ module at low cost $\left(0.3 € / \mathrm{W}_{\mathrm{p}}\right.$ for the power conditioning), and publications on this topics can be found in almost any country with PV activity. These advantages have led to AC modules becoming a relatively good solution in a complex system such as facade-integrated systems. However, this was not so clear in the past, mainly because of technical problems, namely in terms of reliability, cost, and efficiency $[9,10]$. Moreover, the use of multiple AC modules implied the duplication of protections and AC filters, leading to a more expensive solution $[10,11]$. However, some companies such as Enphase and SolarBridge are presently strongly betting on this technology, and they both offer 25-year warranties and claim over $95 \%$ conversion efficiency.

As a consequence, alternative solutions were investigated, and thus, several studies on the implementation of DC-DC converters in PV modules have been made in recent years. The results of these studies have focused on significant technical advances to improve the efficiency [12], MPPT algorithm strategies [13], the analysis of several topologies [11,14,15] and even economical aspects of DC-DC converters [16], this last one being one of the weakest points of this distributed architecture because the cost of the whole PV installation is increased. Nevertheless, it has been demonstrated that this solution turns out viable [16] in certain situations, amongst others: specific applications of PV systems, such as BIPV systems, with high module peak power, and with performance ratio (PR) values under 0.7 ; that is, PV systems with high potential to be improved from the power losses point of view. Proof of this are the many products that have recently invaded the market, well known as "Power Optimizers", companies like SolarEdge, SolarMagic, SunSil, etc., some of these claiming to improve power yields up to $30 \%$. ST Microelectronics has recently announced a new microchip with MPPT, a DCDC converter and various communication options, which they claim will cost $10 €$ if produced in larger quantities: [17] this, applied to a $250-\mathrm{W}$ module only represents a $0.04 € / \mathrm{W}$ increase. However, there is an absence in the literature of aspects such as behavioural models and practical test results in the real operation of MPPT converters in a typical gridconnected PV system. Looking further into these aspects is the objective of this paper based on previous studies $[18,19]$.

This paper is structured in three sections. In the Introduction, a basic concept of a boost MPPT converter, equivalent electronic circuit, conversion ratio, and its behaviour under the operation of PV modules with by-pass diodes is explained. The section on MPPT Converters Concept explains the technical characteristics of the MPPT converter used for the evaluation test and its characterization through a novel method; very simple to implement and very useful for field test measurements without power consumption. Finally, a behavioural analysis study and test results using MPPT converters connected in series and to a central PV inverter, as a classic string PV generator, are presented in the section on MPPT Prototype Characteristics and It's Characterization.

It is important to clarify that the final objective of this paper is to supply an analysis method and test results that allow the verification of the operation of any MPPT converter at specific circumstances. The prototype used here was developed with the intention of serving as a tool to research the behaviour of all MPPT converters integrated in PV modules. The DC-DC converter efficiency and the different topologies analysis are out of the scope of this paper. Although all tests were realised using a boost converter, the analytical study and testing method are suitable for any topology. Hence, the test results are focused on analysing the behaviour of the prototype and comparing its maximum input power (before any power conversion) with the power availability of the PV array and by verifying the correct operation of other parameters: conversion ratio, output voltage of the PV system, and maximum power point location according to shading profile and/or partial dirt.

\section{MPPT CONVERTERS CONCEPT}

The function of the MPPT converter is to keep the working point of the PV generator at, or as close as possible to, the maximum power point (MPP) under all operating conditions such as different irradiation, temperature, and load characteristics.

\subsection{Boost DC-DC converter}

Boost DC-DC converters are widely used in PV inverters as an interface between the PV generator and the DC-AC inverter. On the contrary, the prototype studied in this paper has been designed to operate applied to each PV module, with the aim of extracting its individual maximum power under all potential conditions. To understand the operation of a boost converter, its typical equivalent circuit is shown in Figure 1.

Specific boost topology has the advantage of increasing its input voltage, which is ideal to obtain high output voltages, adapting in a better way to the input voltage range of grid-connected PV inverters. Although other topologies such as buck-boost are also suitable, the boost DC-DC converter is explained because it was the one used for the test. Expression (1) shows how the output voltage is increased if a quick change of the current through the inductor occurs, which depends on the commutation rate 


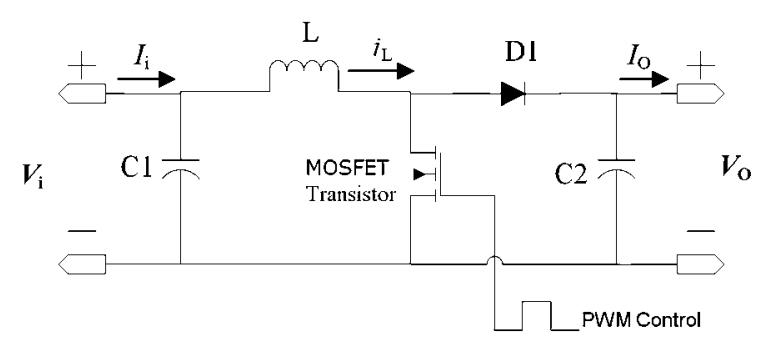

Figure 1. Electrical circuit of a boost converter.

of the MOSFET transistor, controlled by a pulse width modulation (PWM) signal. ${ }^{\prime}$

$$
V_{o}=V_{i}+\frac{\mathrm{d} i_{l}}{\mathrm{~d} t} \cdot \mathbf{L}
$$

Under ideal conditions (the efficiency is considered equal to one as in expression (2)), the solution of the circuit's equations provides the ideal conversion ratio, $M(D)$, between input voltage $V_{\mathrm{i}}$, and output voltage $V_{\mathrm{o}}$, which in a typical boost DC-DC converter is known as follows:

$$
M(D)=\frac{1}{1-D}=\left.\frac{V_{o}}{V_{i}}\right|_{\eta=1}
$$

where $D \in[0,1]$, represents the duty cycle of the PWM control signal, which is applied to the transistor: the frequency is fixed, and $D$ fixes the pulse width of the periodic signal. The relationship between the input current $I_{i}$, and output current $I_{\mathrm{O}}$, with the conversion ratio is not influenced by the efficiency and is known as (3):

$$
\frac{I_{\mathrm{o}}}{I_{\mathrm{i}}}=(1-D)=M(D)^{-1}
$$

The influence of the inductor's internal resistance ${ }^{2}$ turns Equation (2) into a non-linear expression, which is represented as follows:

$$
\begin{aligned}
M_{R}(D) & =\left.\frac{V_{\mathrm{o}}}{V_{\mathrm{i}}}\right|_{\eta \neq 1}=\frac{1}{1+\frac{R_{\ell}}{(1-D)^{2} \cdot Z}} \cdot M(D) \\
& =\eta_{\mathrm{CONV}} \cdot M(D)
\end{aligned}
$$

where $R_{\mathrm{L}}$ is the inductor resistance, and $Z$ is the impedance connected to the output of the converter. The converter's efficiency can also be determined for a non-ideal boost

${ }^{1}$ The PWM signal is automatically changed according to the decisions of the internal MPPT algorithm.

${ }^{2}$ For the sake of simplicity, the inductor is assumed as the only non-ideal component, and that it is equivalent to an inductor and a resistor in series. Furthermore, current flows through the inductor both in the on and the off states, so any non-ideal effects will be more pronounced.

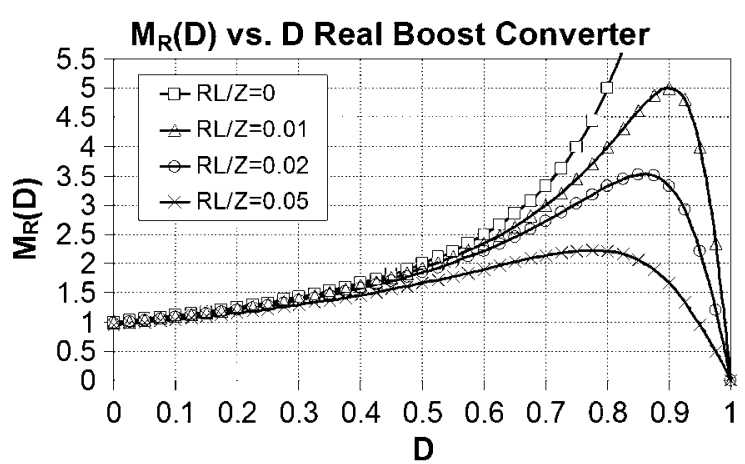

Figure 2. Real conversion ratio $M_{R}(D)$ versus. duty cycle $D$ for a non-ideal boost converter dependent on $R_{\mathrm{L}} / Z$.

converter by means of the relationship of its output power $P_{\text {out }}$ and input power $P_{\text {in }}$, and expressions (3) and (4).

$$
\eta_{\mathrm{CONV}}=\frac{P_{\text {out }}}{P_{\text {in }}}=\left.\frac{V_{o}}{V_{i}}\right|_{\eta \neq 1} \cdot M(D)^{-1}=\frac{1}{1+\frac{R_{L}}{(1-D)^{2} \cdot Z}}
$$

So, in the right side of expression (4), the losses of the converter are represented in terms of the converter's efficiency, $\eta_{\text {CONV. }}$. Broadly speaking, $\eta_{\text {CONV }}$ represents not only the losses in the inductor, but all kinds of losses in the entire DC converter, including self consumption, switching, and conduction losses, for instance, in diode and the MOSFET transistor.

To protect the electronic devices of the converter and limit the switching and conduction losses, it is convenient to limit the output voltage, at a maximum value of $M_{\mathrm{R}}(D)$ (essentially what is limited is $D^{3}$ ). Figure 2 shows the real conversion ratio $M_{\mathrm{R}}(D)$, for different values ${ }^{4}$ of $R_{\mathrm{L}} / Z$ for a non-ideal boost converter, modelled by Equation (4) and how the efficiency can be significantly affected with an increase of $D$ owing to the switching and conduction losses. Another implication of Figure 2 is that the inductor winding resistance $R_{\mathrm{L}}$ limits the maximum voltage that the converter can produce. For example, with $R_{\mathrm{L}} / Z=0.02$, it can be seen that the maximum $V_{\mathrm{o}} / V_{\mathrm{i}}$ is approximately 3.5 .

\subsection{MPPT behaviour under operation in shaded photovoltaic modules with by-pass diodes}

The operation of MPPT converters depend not only on the current decoupling between them, but also on PV module's

\footnotetext{
${ }^{3} D$ is limited by software. However, and owing to non-ideality factors, the $M(D)$ limit will be lower: $M_{R}(D)$.

${ }^{4} R_{L} / Z$ values have been selected by increasing $R_{L}$ at steps of 0 , 100,200 , and $500 \mathrm{mH}$ and by fixing $\mathrm{Z}$ at $10 \Omega$.
} 
or generator's I-V curve, which is affected when any by-pass diode is forward biassed under circumstances such as dirt or shadows. These situations generate two or more MPPs in the I-V curve. The MPPT converter will work at one of the MPPs, not necessarily the absolute MPP. Therefore, the MPPT's behaviour is strongly influenced by the I-V curve's shape, it being influenced mainly by two aspects: covered area and the diode activation zone. In this specific situation, the well functioning of the MPPT converter depends on the location of the absolute MPP.

To understand the phenomenon, suppose one shadow crossing a PV module in a string, in such a way that one by-pass diode is forward biassed. Figure 3 shows the measurement of two $\mathrm{I}-\mathrm{V} / \mathrm{P}-\mathrm{V}$ curves. Whereas a $\mathrm{PV}$ cell is shaded less than 70\% (left graph), the absolute MPP is the one with a higher voltage in the $\mathrm{P}-\mathrm{V}$ curve, and the diode is in reverse bias. However, when the shaded area exceeds this limit (approximately 70\%), the absolute MPP moves to the lower voltage of the PV curve, and thus, current decoupling disappears because the by-pass diode goes into forward bias; however, all of that PV module's power is lost. This fact provides two important and contrasting conclusions: according to expression (3), the MPPT converter integrated in a PV module works well at eliminating decoupled currents of less than $70 \%$; however, when these values are higher than $70 \%$, the decoupling current disappears, the diode is forward biassed, and the MPPT converter does not improve the decoupling of the PV module.

\section{PROTOTYPE CHARACTERISTICS AND IT'S CHARACTERIZATION}

This section explains the technical characteristics of the MPPT converter used for the evaluation test. It has been developed with partial funding from the Spanish 'Ministerio de Industria' and built by TECNALIA $[1,20]$
Finally, a novel characterization method is used to test the prototype.

\subsection{Boost maximum power point tracking converter prototype}

The prototype consists of a boost DC-DC converter, which is applied directly to the PV module and incorporates an MPPT algorithm, a control unit with supervision and failure detection functions, and a PLC system to transmit the information to a supervision control unit (SCU).

After a deep evaluation of the potential of DC-DC conversion topologies in terms of complexity, cost, and conversion efficiency, the boost converter (also known as the step-up converter) has been selected because it has been considered a suitable option for the BIPV applications owing to its simplicity, low cost, and higher efficiency. Other topologies could be similar in terms of complexity and efficiency (buck converter and buck-boost) and even better in specific mismatched working conditions (e.g., buck-boost converter). A simplified electrical diagram of this topology is shown in Figure 1.

The boost converter always provides a higher output voltage than its input. This characteristic is especially convenient to achieve the voltage required by the inverter, when only a few PV modules are connected, and also allows working with lower string output currents, consequently reducing wiring losses (Table I).

Choosing small sizes of capacitors, inductors, etc., makes the boost converter suitable to be mounted behind the PV panel, inside the connection box because of its minimum number of components and reduced space needed for the printed circuit board. The latest one to be announced only has one integrated circuit and 33 other electronic components, occupying only about one-fourth of a solar cell [17]. Figure 4 shows the aspect of the implemented $\mathrm{DC}-\mathrm{DC}$ converter prototype. The components of the DC-DC converter have been carefully selected to
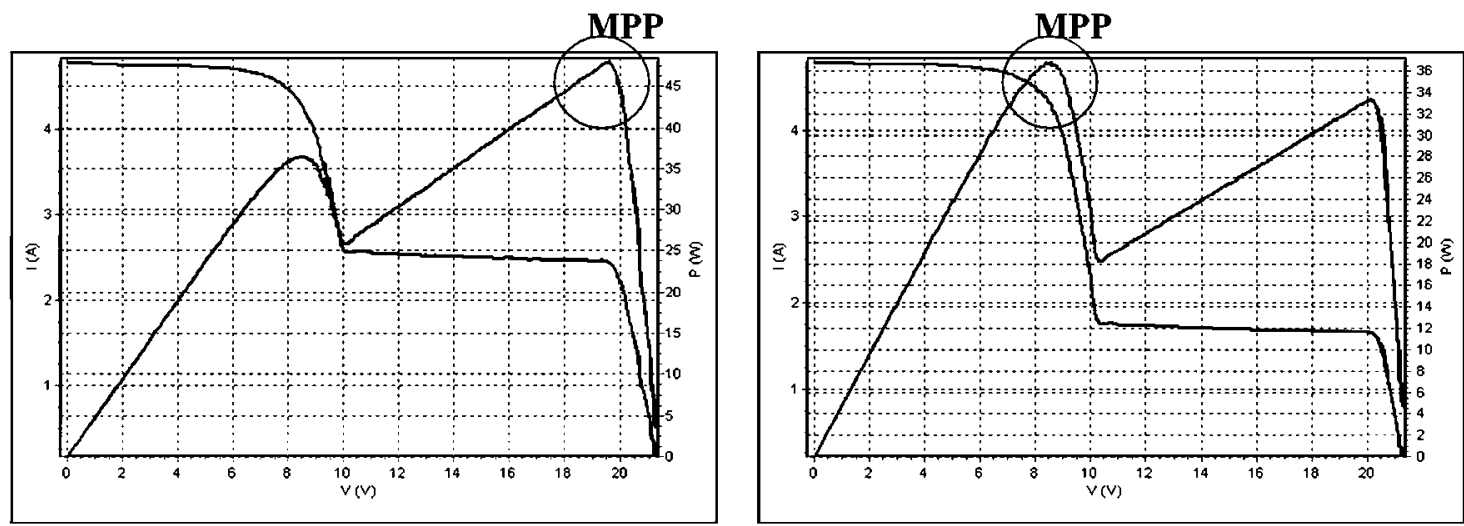

Figure 3. Measurement results of a photovoltaic module (two series bypass diodes) with a shadow over one PV cell; on the left $50 \%$ and on the right $75 \%$. 
Table I. Summary of the electrical parameters of the DC-DC converter.

\begin{tabular}{ll}
\hline Parameter & \multicolumn{1}{c}{ Working range } \\
\hline Working temperature & $-15^{\circ} \mathrm{C}$ to $+70^{\circ} \mathrm{C}$ \\
Input voltage & $3.24-40 \mathrm{VDC}$ \\
Input current (depending on the $\left.V_{\mathrm{PV}}\right)$ & $0 \mathrm{~A}-10 \mathrm{~A}$ \\
Maximum input power & $200 \mathrm{~W}$ \\
Conversion ratio $M(D)$ & $1: 3$ \\
(Input voltage: output voltage) & \\
Maximum output voltage & $50 \mathrm{~V}$ \\
Maximum output current & $10 \mathrm{~A}$ \\
Maximum output power & $200 \mathrm{~W}$ \\
Power conversion & $90 \%-95 \%$ at $P>100 \mathrm{~W}$ \\
efficiency, $\eta_{\text {Conv }}$ & and $M(D)<3$ \\
\hline
\end{tabular}

enhance their performance. Thus, both the MOSFET and the Schottky diode have been chosen to minimise conduction and switching losses. Additionally, the inductor and the capacitors have been used with low series resistance, or equivalent series resistance, which implies a low power loss in both elements.

The MPPT algorithm finds and maintains operation at the MPP. Many such algorithms have been proposed in the literature $[21,22]$. However, it is difficult to find standardised comparisons or appropriate methods for determining MPPT performance, apart from the works of Jantsch et al. and Sanchis et al., [23,24] where methods to measure the accuracy, error, and efficiency of MPPT algorithms have been presented. Using these guidelines, a wide variety of available MPPT techniques and possible modifications and improvements have been analysed. The scope of the study was limited to those algorithms thought to be applicable to low-cost implementations. Many algorithms such as short-current, pulse-based methods, or the two-stage method, were not considered because of their uncertain efficiency or clear complexity. After this first analysis, only two hill-climbing methods were seriously considered, namely: (1) the perturb and observe (P\&O) method and (2) the incremental conductance (InCond) method. Whereas the former continues to be by far the most widely used method in commercial PV MPPT, the latter usually appears in the literature as a progress in efficiency. In fact, the incremental conductance method was developed to avoid the drawbacks of the P\&O method.

The InCond method is based on the fact that the derivative of the output power $P$, with respect to the panel voltage $V$, is equal to zero at the MPP. The $\mathrm{P}-\mathrm{V}$ characteristics show that the derivative is greater than zero to the left of the MPP and less than zero to the right. Appropriate equations lead to the MPP condition in terms of the PV module voltage $V$, and current $I$. Therefore, enough information is gathered to determine the relative location of the MPP by measuring only the incremental and instantaneous module conductance, $\mathrm{d} I / \mathrm{d} V$ and $I / V$, respectively. Herein lays a primary advantage of this method over the $\mathrm{P} \& \mathrm{O}$ algorithm. Incremental conductance can actually calculate the direction in which to perturb the operating point to reach the
MPP. Thus, under rapidly changing conditions, it should not track in the wrong direction, as P\&O can. Another advantage of this MPPT algorithm is that it does not oscillate around the MPP once it reaches MPP because it can determine when it has actually reached MPP. However, the maximum power condition is only rarely achieved because it is very difficult to adjust the voltage to the exact MPP when using a constant adjustment step width. To solve this problem, a small marginal error is added to the maximum power condition. The final implementation is a mixed solution: InCond method with light modifications.

\subsection{MPPT converter characterization method}

The typical method used to characterise DC-DC converters at laboratory level is by means of a DC power supply. The new method proposed presents the following advantages: no power consumption, automatic trace of electrical curves in $10 \mathrm{~s}$, useful instrumentation to measure on site, and two electrical characterizations at the same time (PV module and its MPPT converter associated). It is important to clarify that the objective of this method is to verify the correct operation of any MPPT converter, but not its efficiency, which is a characteristic of its electronic design, which can be drastically improved during the industrialization process.

To analyse both the behaviour and the $M(D)$ limit of the MPPT converter, it is necessary to characterise their $\mathrm{P}-\mathrm{V}$ and $\mathrm{I}-\mathrm{V}$ curves. For that purpose, a capacitive load already developed in the IES-UPM [25] has been used to sweep the $\mathrm{P}-\mathrm{V}$ curve of the MPPT converter, as is shown in Figure 5. The capacitor $(0.3 \mathrm{~F})$ is charged very slowly by the PV module through the converter, so that it provides enough time for the MPPT algorithm to track the MPP. A datalogger is used to measure the input and output values of voltages and currents.

The charge time $\tau_{\mathrm{c}}$, of the capacitor is calculated using expressions (3) and (4), which leads to:

$$
\tau_{\mathrm{c}}=\frac{V_{\mathrm{m}}}{I_{\mathrm{m}}} \cdot M_{R}(D)_{\mathrm{MAX}}{ }^{2} \cdot C
$$

This equation relates the maximum voltage $V_{\mathrm{m}}$, the maximum current $I_{\mathrm{m}}$, of the PV module, the maximum real conversion ratio $M_{\mathrm{R}}(D)_{\mathrm{MAX}}$, and the capacitance $C$.

Simulation results (using Simulink Matlab) have revealed that the average time used by the converter to find the MPP is about $100 \mathrm{~ms}$ (for the prototype used) and $250 \mathrm{~ms}$ in the worst case. The electrical parameters of the PV module and MPPT converter are: $V_{\mathrm{m}}=17 \mathrm{~V}, I_{\mathrm{m}}=4.05 \mathrm{~A}$ at standard test conditions ${ }^{5}$ and $M_{\mathrm{R}}(D)_{\mathrm{MAX}}=2.4$. In this situation, the shortest charge time that can be obtained is

\footnotetext{
${ }^{5}$ Standard test conditions: reference values of in-plane irradiance $\left(\mathrm{G}_{\text {ref }}=1000 \mathrm{~W} / \mathrm{m}^{2}\right)$, PV cell junctiontemperature $\left(25^{\circ} \mathrm{C}\right)$, and air mass (AM $=1.5$ ), according to IEC standards.
} 


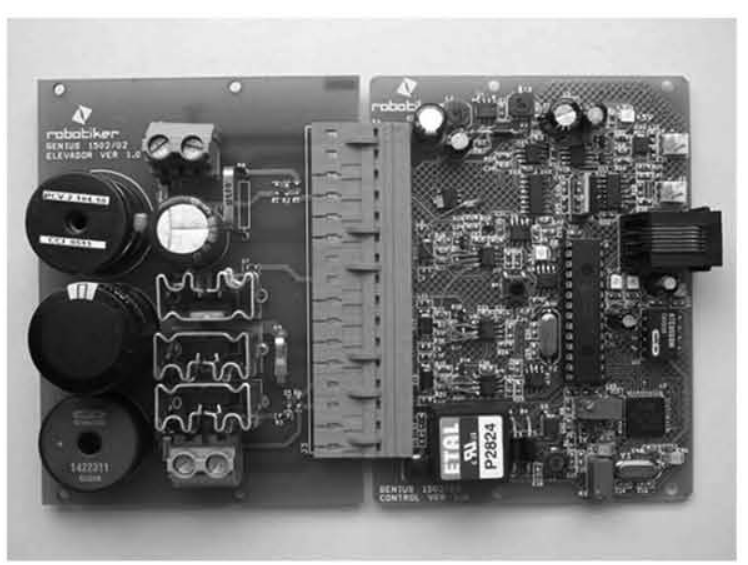

Figure 4. Maximum power point tracking prototype.

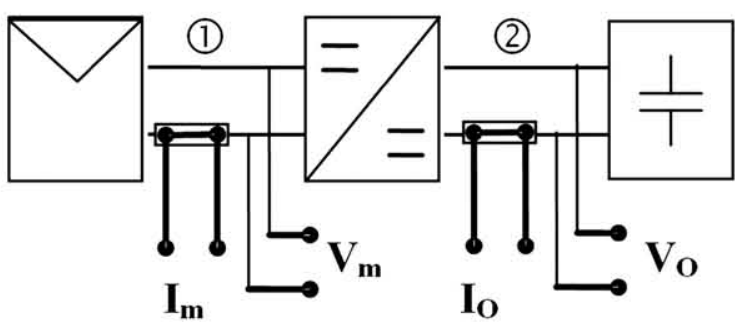

Figure 5. Block diagram to characterise the maximum power point tracking converter.

approximately $7.5 \mathrm{~s}$. However, the charge curve is exponential, and the sample time is constant. This means that fewer points are obtained during the early charging stage (with the most important data) and more in the final charging stage (with the less important data). This can be a problem if a precise measurement is required. However, at lower irradiance, more samples can be obtained. At $500 \mathrm{~W} / \mathrm{m}^{2}, 25$ useful points in MPPT zone during $15 \mathrm{~s}$ of charging time have been obtained, which is a reasonable quantity to describe the curves and to validate the correct operation of the MPPT converter.

The resulting $\mathrm{I}-\mathrm{V}$ and $\mathrm{P}-\mathrm{V}$ curves are detailed in Figure 6. The graph shows the working points of the PV module and the output curve of the PV module with DC-DC converter, measured simultaneously.

The graph with the "_-" symbol represents the PV module operation points at (1) in Figure 5. The MPP is located at average values of $V_{\mathrm{m}} \cong 13.8 \mathrm{~V}$ and $I_{\mathrm{m}} \cong 2.24 \mathrm{~A}$. The graph with the " symbol, represents the I-V curve at (2) in Figure 5 (PV module + DC-DC converter). Once the MPPT is found by the DC-DC converter, the converter provides a range of voltage in which the power is maximum, and equal to the MPP. The constant power hyperbola is obtained in accordance with the voltage increasing, and the current decreasing proportionally, maintaining the PV module at maximum power. This constant power area starts from a PV module voltage of about $13.8 \mathrm{~V}, M_{\mathrm{R}}(D)=1$, until $M_{\mathrm{R}}(D)_{\mathrm{MAX}}=2.4$ is reached,

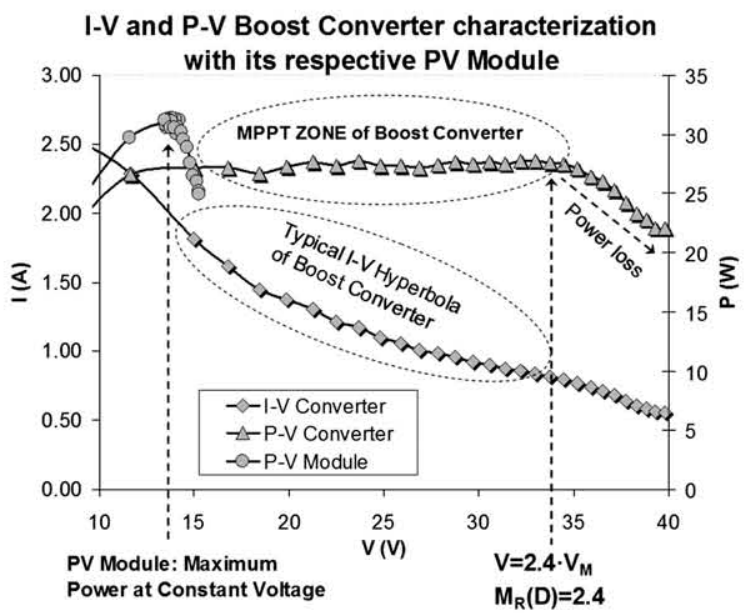

Figure 6. Boost maximum power point tracking converter characterization.

at about $33 \mathrm{~V}$. Having a look at the P-V curve at (2) in Figure 5 (PV module + DC-DC converter), represented by the graph with the " symbol, it can be observed that the input power becomes constant in the MPPT zone. The MPPT zone in the graph (highlighted in Figure 6) shows the correct operation of the MPPT converter, which verifies how it is able to maintain ( $\pm 1 \%$ variation) the PV module at its maximum power, of about $31 \mathrm{~W}$ at the converter input and $28 \mathrm{~W}$ at the output. The relationship between both power values, output, and input, is the converter efficiency.

\section{MPPT CONVERTERS IN PHOTOVOLTAIC ARRAYS}

The idea of integrating MPPT converters to each PV module makes sense when they are connected in cascade, as a classic string PV generator, and in parallel with a PV inverter in a typical grid-connected PV system.

\subsection{Description of the photovoltaic system under test}

The system under test is made up of four MPPT converters connected in series and all together to the PV inverter. The block diagram of the proposed system is shown in Figure 7, where the following main parameters can be identified: voltage $V_{\mathrm{i}}$ and current $I_{\mathrm{i}}$, of each 'i' PV module, which corresponds to the input parameters of the MPPT converters; converter output voltage $V_{\mathrm{Oi}}$, and system output current $I_{\mathrm{O}}$, are the output parameters, and irradiance $G$, and temperature of PV modules, $T_{\mathrm{m}}$, are the measurement (environmental) conditions. All the currents are measured with calibrated shunt-resistance sensors. The PV inverter used is the SMA Sunny Boy 700 inverter (SMA Ibérica Tecnología Solar, S.L., España), which allows selecting a constant voltage at its input. Other parameters, such as its 


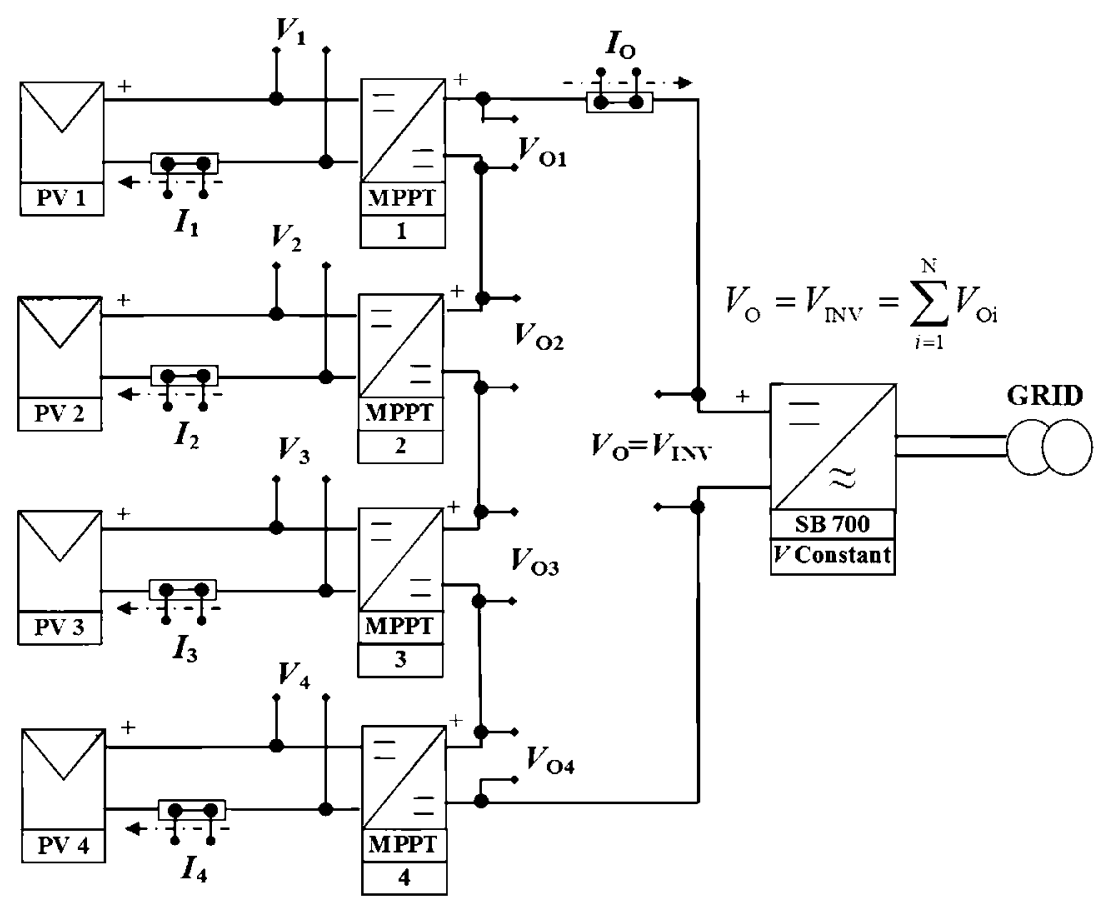

Figure 7. Block diagram of the test system, made up of four maximum power point tracking converters in cascade connected to a photovoltaic inverter in a typical grid-connected photovoltaic system.

input voltage range (three different voltage ranges are available), can be configured by the final user in an easy manner.

The electrical parameters of the MPPT converters, and their accordance, are presented in Figure 7. On the one hand, the global output voltage $V_{\mathrm{O}}$, must be always equal to the sum of the output voltages of the MPPT converters and to the input voltage of the inverter $V_{\mathrm{INV}}{ }^{6}$. The inverter voltage is imposed in the system as the operating voltage and subsequently each MPPT converter is also influenced by this value. And, on the other hand, the output current $I_{\mathrm{O}}$, is the same for all the MPPT converters in the string. Consequently, the minimum $I_{O}$ of any MPPT converter forces the others to work by driving this current.

The expression of non-ideal MPPT converters, which relates the converter efficiency ${ }^{7} \eta_{\mathrm{CONV}}$, with the electrical parameters of the PV modules $V_{i}$ and $I_{i}$, and the output parameters $I_{\mathrm{O}}$ and $V_{\mathrm{O}}$, of the MPPT converter is as follows:

$$
I_{O}=\frac{\sum\left(\mathrm{V}_{i} \cdot I_{i}\right)}{\mathrm{V}_{\mathrm{INV}}} \cdot \eta_{C O N V}
$$

${ }^{6}$ From now on, $V_{\text {INY }}$ will be used as the system's output voltage, equal to the sum of all converter output voltages.

${ }^{7}$ To simplify, the same efficiency for all MPPT converters and its independence from input power is assumed. If this simplification is not considered, the parameter must be changed for each ' $i$ ' MPPT converter, that is, $\eta_{\text {Conv. } i}$
The $V_{\text {INV }}$ is imposed in the system, and consequently, it forces all MPPT converters to work at current $I_{\mathrm{O}}$. Using Equation (3) and replacing $I_{\mathrm{O}}$ in Equation (7), two expressions for the conversion ratio of each , $i$ ' MPPT converter $M(D)_{i}$, are obtained:

$$
\begin{gathered}
M(D)_{\mathrm{i}}=\frac{I_{\mathrm{i}}}{\sum\left(I_{\mathrm{i}} \cdot V_{\mathrm{i}}\right)} \cdot \frac{V_{\text {INV }}}{\eta_{\mathrm{CONV}}} \\
M(D)_{\mathrm{i}}=\frac{\boldsymbol{I}_{\mathrm{i}}}{\sum\left(I_{\mathrm{i}}\right)} \cdot \frac{V_{I N V}}{V_{\mathrm{i}}} \cdot \frac{1}{\eta_{\mathrm{CONV}}}
\end{gathered}
$$

Expression $^{8}(8)$ is used for all operating conditions. However, in expression (9), the current and voltage terms are separated with the purpose of understanding the influence of the operating condition of the PV module. To simplify expression (7) and to identify the influence of the current decoupling between PV modules, it is assumed as an approximation that all PV modules have the same voltage $V_{\mathrm{i}}$. At uniform irradiance over the entire surface of the PV modules, the first term of expression (8) (ratio between currents) does not change with the irradiance level, thus $M(D)$ is constant in all converters. However, the second term (ratio of voltages) depends on the $V_{i}$ parameter (voltage of the ' $\mathrm{i}$ ' PV module), which is strongly influenced by cell temperature and inverter voltage $V_{\text {INV. }}$

\footnotetext{
${ }^{8}$ According to expression (4), the conversion rate in real operation $M_{\mathrm{R}}(D)_{\mathrm{i}}=M(D)_{\mathrm{i}} \cdot \eta_{\text {CONv }}$ must be used.
} 
The third term is the efficiency of the MPPT converter. However, in this expression, two approximations are considered: (1) the efficiency is constant and independent of the power, and (2) the cell temperature is the same for all PV modules in the string. In conclusion, to keep $M(D)$ within the limits of the MPPT converters, $V_{\mathrm{INV}}$ must be calculated carefully, and it should be analysed with each specific case of decoupling currents using the relation $I_{\mathrm{i}} / \Sigma I$ as the main factor.

\subsection{Analytical models to describe the current decoupling phenomenon in cascade MPPT converters}

When the current of any specific PV module connected to its MPPT converter is lower than the rest of the currents in the string, owing to shading or different tilt and orientation angles, the current decoupling phenomenon occurs. The main function of the MPPT converters applied to the module is to adapt its output voltage and current to isolate this effect.

However, the optimum operation of MPPT converters is limited, as a result of three main parameters: (1) maximum and minimum conversion ratio, (2) maximum current decoupling between PV modules, and (3) the voltage imposed by the PV inverter.

When the decoupling phenomenon is produced in one PV module, the output current of the associated MPPT converter decreases with respect to the others connected in series; subsequently, by Kirchhoff's circuit laws, they also decrease their $I_{\mathrm{O}}$. On the one hand, to keep the power stable in other MPPT converters, they will increase their output voltage $V_{\mathrm{O}}$ proportionality, but only up to its maximum conversion ratio. On the other hand, the MPPT converter associated to the decoupled PV module must decrease its $V_{O}$ (and therefore, increase its $I_{O}$ ) to maintain the input voltage imposed by the PV inverter, but only down to the absolute minimum conversion ratio, $M(D)_{\mathrm{MIN}}=1$. In essence, what occurs is that the $M(D)$ of the decoupled module decreases, and the $M(D)$ of the non-decoupled modules increases. All of it, of course, between $M(D)$ limits and always respecting the voltage imposed by the inverter. In both cases, if any MPPT converter is out of $M(D)$ limits, it will imply a power loss in the system

With this analysis, the condition of the maximum conversion ratio, $M(D)_{\mathrm{MAX}}{ }^{9}$ and minimum conversion ratio $M$ $(D)_{\mathrm{MIN}}$, which occur in any particular situation in a PV system with MPPT converters, can be extracted from expression (8), resulting in the following expressions:

${ }^{9}$ These are not the absolute limits of the system, but those that occur in a certain situation.

$$
\begin{gathered}
M(D)_{\mathrm{MAX}}=\frac{V_{I N V}}{V \cdot \sum_{\mathrm{i}}\left(1-D E C_{i}\right) \cdot \eta_{\mathrm{CONV}}} \\
M(D)_{\mathrm{MNV}}=\frac{\left(1-D E C_{M A X}\right) \cdot V_{I N V}}{V \cdot \sum_{\mathbf{i}}\left(1-D E C_{i}\right) \cdot \eta_{\mathrm{CONV}}} \\
D E C_{i}=1-\frac{I_{i}}{\max (I)}
\end{gathered}
$$

Where $D E C_{\mathrm{i}}$ represents the decoupling current ratio for each PV module ' $i$ ' in comparison with the maximum current in the string, $D E C_{\mathrm{MAX}}$ being the maximum decoupling ${ }^{10}$ in the string and $V$ corresponds to the operating voltage of the PV modules, assumed equal. In practice, $M(D)_{\text {MN }}$ is the value that corresponds to the MPPT converter applied to the PV module strongly affected by shadows or other current decoupling effects. On the contrary, $M(D)_{\text {MAX }}$ corresponds to those less affected modules.

\subsection{Determining the optimum input voltage of a grid-connected photovoltaic inverter}

\subsubsection{General expression in terms of decoupling currents.}

The PV inverter should be configured in constant voltage mode, which means setting off its MPPT function. The inverter used allows the choice between constant voltage mode and MPPT mode.

A simplified form for calculating $V_{\mathrm{INV}}$ can be used by simplifying Equations (10) and (11), where all shaded PV modules are considered with the same amount of shade, and the rest are non-shaded, and where the absolute values for $M(D)$ are used. This study should be carried out for the worst case scenario, for example, the exact moment of the year when most shade occurs. As a consequence, the following two expressions for $V_{\mathrm{INV}}$ are obtained:

$$
\begin{array}{r}
V^{\prime} \mathrm{INV}=V \cdot M_{R}(D)_{\mathrm{MAX}} \cdot\left(N_{\mathrm{SM}}(1-D E C)+\left(N_{\mathrm{M}}-N_{\mathrm{SM}}\right)\right) \\
V^{\prime}{ }_{\mathrm{INV}}=V \cdot M_{R}(D)_{\mathrm{MIN}} \cdot \frac{\left(N_{\mathrm{SM}}(1-D E C)+\left(N_{\mathrm{M}}-N_{\mathrm{SM}}\right)\right)}{N_{\mathrm{SM}}(1-D E C)}
\end{array}
$$

where $N_{\mathrm{M}}$ is the quantity of MPPT converters in the string; $N_{\text {SM }}$ is the number of shaded modules in the string; $V^{\prime}{ }^{-}$INV in (12) represents the PV inverter voltage when the nonaffected converters reach $M_{\mathrm{R}}(D)_{\mathrm{MAX}}{ }^{11} ; V^{\prime \prime}{ }_{\mathrm{NV}}$ in (13)

\footnotetext{
${ }^{10}$ Maximum decoupling means maximum differences between currents in a specific case. The absolute maximum DEC value is one, and the equivalent minimum is zero (no decoupled current).

${ }^{11}$ As an approximation, the same $M(D)$ value of the non-affected MPPT converters is assumed. In real measurements, differences between them lower than $5 \%$ have been confirmed.
} 


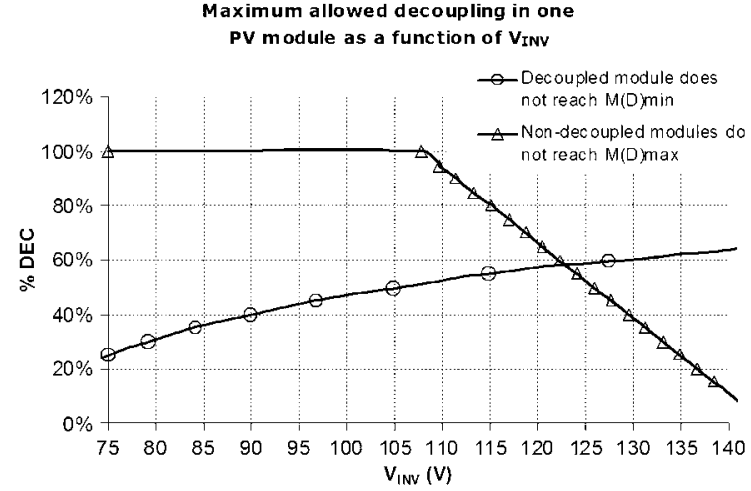

Figure 8. Example graph which relates the optimum $V_{\text {INV }}$ and maximum current decoupling $D E C$, in a system made up of four maximum power point tracking converters in cascade.

represents the PV inverter voltage for the specific decoupled PV module whose connected converter reaches $M_{\mathrm{R}}(D)_{\mathrm{MIN}}$. The $M_{\mathrm{R}}(D)$ value has been considered as a measured value; according to the analysis of expression (4), the converter efficiency is already included in expressions (12) and (13).

Figure 8 shows the relationship between optimal $V_{\mathrm{INV}}$ and $D E C$, using (12) and (13) for the specific system used in the test and considering only one shaded module. The characteristic values are: $M_{\mathrm{R}}(D)_{\mathrm{MAX}}=2.4, V=15 \mathrm{~V}$ (maximum voltage at $T_{\mathrm{c}}=50^{\circ} \mathrm{C}$ ) and $I=4.05 \mathrm{~A}$ (maximum current at $1000 \mathrm{~W} / \mathrm{m}^{2}$ ). The graph shows that the optimal $V_{\text {INV }}$ is about $105 \mathrm{~V}$, for four MPPT PV modules. At this voltage, the non-affected converters will not reach $M(D)$ $\operatorname{MAX}{ }^{12}$ even if $100 \%$ current decoupling occurs. On the other hand, the affected converter's maximum decoupling can be up to $50 \%$ without reaching $M(D)_{\mathrm{MIN}}$, avoiding the additional losses because of $M(D)$ limits.

The idea is to guarantee that the majority of modules, the non-affected ones, do not suffer power losses because of $M(D)$ limits. One could think that the optimum value of $V_{\text {INV }}$ is $123 \mathrm{~V}$, where both curves meet, and a current decoupling of almost $60 \%$ can occur without any converter reaching $M(D)$ limits. However, this small gain in maximum decoupling $10 \%$, is negligible compared with the detrimental effect, for the non-affected modules, if higher decoupling values occur. Therefore, higher values for $V_{\mathrm{INV}}$ are not recommended. When $D E C$ is maximum, expression (12) can be simplified to Equation (14), which provides an easier expression to calculate $V_{\mathrm{INV}}$, assuring that $100 \%$ decoupling can occur in one module without it affecting the rest of the modules:

$$
V_{\mathrm{INV}}=V \cdot\left(N_{\mathrm{M}}-N_{\mathrm{MS}}\right) \cdot M_{\mathrm{R}}(D)_{\mathrm{MAX}}
$$

It is important to note that there is a limit to the number of modules that can be fully shaded in the system. If the

${ }^{12}$ It is the same as saying $M_{R}(D)$, also for $M(D)_{\text {MIN }}$ and for Figure 8. ratio of shaded to non-shaded modules is too large, that is, six out of 10 , the optimum $V_{\mathrm{INV}}$ would be so small, $144 \mathrm{~V}$ in our case, and that it would not permit a correct functioning of the system in non-shaded conditions: because $M(D)_{\mathrm{MIN}}$ is one, the minimum voltage is $150 \mathrm{~V}$.

\subsubsection{Considering different tilt and orientation angles.}

Different tilts and orientation angles are a typical case of BIPV, where architectural integration plays an important role in the PV system. The former expressions are focused on the current decoupling of one PV module in the string. In the case of different inclinations and orientations, the decoupling term must be changed by the irradiance level ${ }^{13}$ on different surfaces, and where all PV modules in the string are considered.

$$
M(D)_{i}=\frac{I_{i}}{I_{\mathrm{MAX}} \sum\left(1-D e c G_{i}\right)} \cdot \frac{V_{\mathrm{INV}}}{V} \cdot \frac{1}{\eta_{\mathrm{CONV}}}
$$

With,

$$
\sum I_{i}=I_{\mathrm{MAX}} \cdot \sum\left(1-D e c G_{i}\right)
$$

and

$$
D e c G_{i}=1-\frac{G_{i}}{G_{\mathrm{MAX}}}
$$

Where $G_{\mathrm{i}}$ is the irradiance for a specific situation ' $\mathrm{i}$ ' of tilt and orientation $G_{\mathrm{MAX}}$ is the maximum irradiance situation in the string, and $\operatorname{Dec}_{i}$ is the decoupling irradiance ratio for each PV module.

Therefore the maximum conversion ratio $M(D)_{\mathrm{MAX}}$, takes place when $I$ is maximum and $V$ is minimum, that is:

$$
\begin{aligned}
M(D)_{\text {MAX }} & =\frac{I_{\mathrm{MAX}}}{I_{\mathrm{MAX}} \sum\left(1-\operatorname{Dec} G_{i}\right)} \cdot \frac{V_{\mathrm{INV}}}{V_{\mathrm{MIN}}} \cdot \frac{1}{\eta_{\mathrm{CONV}}} \\
& =\frac{1}{\sum\left(1-\operatorname{Dec} G_{i}\right)} \cdot \frac{V_{I N V}}{V_{M I N}} \cdot \frac{1}{\eta_{\mathrm{CONV}}}
\end{aligned}
$$

And the voltage of the inverter is:

$$
V_{I N V}=M(D)_{\mathrm{MAX}} \cdot \sum\left(1-D e c G_{i}\right) \cdot V_{\mathrm{MIN}} \cdot \eta_{C O N V}
$$

Generally speaking, in BIPV, there are several PV modules with the same tilt and orientation (same 'i' situation), therefore, in expression (19), the $N_{\mathrm{i}}$ parameter can be added, which represents the amount of PV modules with the same ' $i$ ' conditions. Consequently, expression (19) can be expressed as $(20)$ :

$$
V_{I N V}=M(D)_{\mathrm{MAX}} \cdot \sum N_{i} \cdot\left(1-D e c G_{i}\right) \cdot V_{\mathrm{MIN}} \cdot \eta_{\mathrm{CONV}}
$$

\footnotetext{
${ }^{13}$ Irradiance ratio is equivalent to current ratio.
} 


$$
I_{O \cdot i}=I_{O}=\frac{\sum N_{i} \cdot P_{i}}{V_{\mathrm{INV}}} \cdot \eta_{\mathrm{CONV}}
$$

And the output voltage of each MPPT converter is

$$
V_{O \cdot i}=\frac{P_{i}}{I_{O}} \cdot \eta_{\mathrm{CONV}}
$$

\subsection{Behaviour of MPPT converters using a progressive shadow profile}

The objective of this test is to analyse the behaviour of MPPT converters, when one PV module is covered by a progressive shadow profile on its surface, as shown in Figure 9. It permits to analyse how MPPT converters work in practice: on the one hand, to understand the tracking of the MPP (potential variations of the MPPT algorithm), and on the other hand, to identify the conversion ratio limits.

Table II shows the test measurement results. The PV module of the 'MPPT_1' converter has been selected for the shading test. Three parts are identified in the table; the first one is the percentage of covered area located over each by-pass diode zone (D1 and D2 zones) and the measurement conditions, irradiance and temperature; the second one is the output electrical parameters of the entire PV system; and the third one is the input and output electrical parameters of each MPPT converter.

Progressive shading up to $60 \%$ on the D1 zone: input voltage of the MPPT_1 is in the upper voltage of its P-V curve, and the decoupling current ratio is proportional to the shading level. Its output voltage decreases as well as its $M_{\mathrm{R}}(D)^{14}$, whereas other MPPT converters increase their output voltage and their $M_{\mathrm{R}}(D)$.

Progressive shading from 60 to $100 \%$ on the D1 zone: the bypass diode is in forward bias, and therefore, the MPP moves to the lowest voltage of the P-V curve and the current returns to 'no current decoupling' condition. In this situation, the MPPT converter cannot improve the decoupling of the PV modules.

Shading at $100 \%$ on the D1 zone and progressive shading up to $100 \%$ on the D2 zone: this condition shows a clear decoupling current of the PV module, which is proportional to the shading level. $M_{\mathrm{R}}(D)$ of the MPPT_1 decreases quickly whereas others increase. The critical moment takes place when the power of the PV module is so low that it cannot supply energy to the electronic circuits of the MPPT_1 converter, and thus, it is switched off. At this moment, other converters move to the

\footnotetext{
${ }^{14} M_{R}(D)$ is represented here because they are real measurements, although the same occurs with $M(D)$.
}

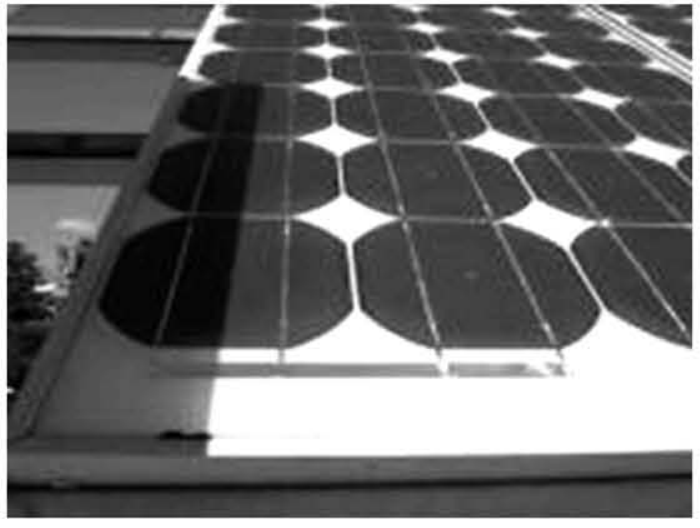

Figure 9. Shadow profile moving over the surface of photovoltaic module.

maximum conversion ratio of 2.3. With this result, the optimum input voltage of a grid-connected PV inverter (section on Determining the Optimum Input Voltage of a Grid-connected PV Inverter) can be verified.

As a practical exercise, these test results can be compared with the expressions exposed in the section on Analytical Models to Describe the Current Decoupling Phenomenon in Cascade MPPT Converters. In Table II, each row is a point of operation of the PV system at the voltage fixed by the PV inverter. First, it is necessary to calculate the output current of total system $I_{O}$, by using expression (6). The converter's efficiency can be extracted from its characterization (section on MPPT Converter Characterization Method), which is considered constant for all converters at $88 \%$. For instance, for the row that corresponds to $30 \%$ of shadow on D1, the output current is calculated as

$$
\mathrm{I}_{O}=\frac{\sum\left(\mathrm{V}_{i} \cdot \mathrm{I}_{\mathrm{i}}\right)}{\mathrm{V}_{\mathrm{INV}}} \eta_{\mathrm{CONV}}=\frac{204 \mathrm{~W}}{105 \mathrm{~V}} 88 \%=1.7 \mathrm{~A}
$$

The maximum and minimum conversion ratios can be also obtained by using expression (9) and $M_{R}(D)$ with (4),

$$
\begin{aligned}
M_{R}(D)_{\mathrm{MAX}} & =M(D)_{\mathrm{MAX}} \eta_{\mathrm{CONV}}=\frac{V_{\mathrm{INV}}}{V \cdot \sum_{i}\left(1-D E C_{i}\right)} \\
& =\frac{105 V}{15.4 V\left(\frac{12.95 \mathrm{~A}}{3.58 \mathrm{~A}}\right)}=1.88
\end{aligned}
$$

And the minimum conversion ratio is calculated as follows,

$$
\begin{aligned}
M_{R}(D)_{\mathrm{MIN}} & =M(D)_{\mathrm{MIN}} \eta_{\mathrm{CONV}}=\frac{\left(1-D E C_{\mathrm{MAX}}\right) \cdot V_{\mathrm{INV}}}{V \cdot \sum_{i}\left(1-D E C_{i}\right)} \\
& =\frac{\left(\frac{2.35 A}{3.58 A}\right) 105 \mathrm{~V}}{15.4 V\left(\frac{12.95 A}{3.58 A}\right)}=1.23
\end{aligned}
$$

Also, the $M_{R}\left(D_{) i}\right.$ of each individual MPPT converter can be obtained by using the expression (7). It can be 


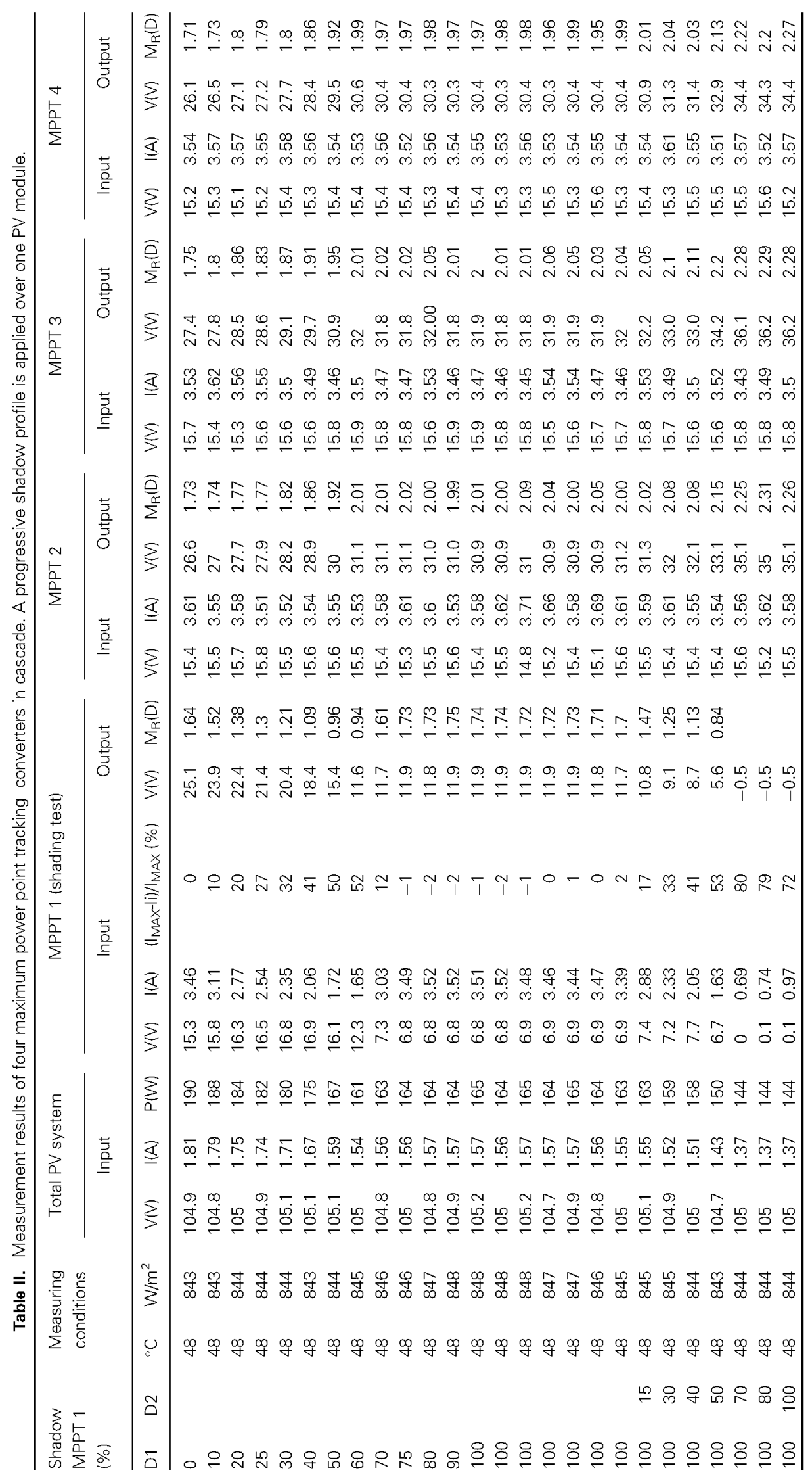


seen that the theoretical results coincide pretty well with the practical ones.

\subsection{Reaching the input power maximisation using MPPT strategy under punctual shading}

In this chapter, the methods and expressions previously exposed have been considered to configure the PV system under test.

The objective of this test is to study the specific situations, where it is possible to extract the maximum power of a PV generator in a typical grid connected PV system, where specific localised shadow conditions have been imposed by using MPPT converters. To evaluate the MPPT strategy, the input power $P_{\mathrm{MPPT}}$ of the MPPT converters has been compared with the power available in the PV generator $P_{\mathrm{G}}$ (absolute MPP fixed by a hypothetic PV inverter) by measuring its I-V curve using a capacitive load [24], which has been also used for the characterization of MPPT converters. For convention in this analysis, the power ratio between both systems is called the ideal improvement factor' of the MPPT strategy $F_{\mathrm{I}}$, which is calculated as follows:

$$
F_{\mathrm{I}}=\frac{P_{\mathrm{MPPT}}-P_{\mathrm{G}}}{P_{\mathrm{G}}}
$$

Taking for granted that shading situations on the PV generators are unlimited, specific situations in accordance with the analysis studied in the section on Behaviour of MPPT Converters using a Progressive Shadow Profile have been considered. The following five types of local shading over each by-pass diode's influence zone, have been considered:

(i) One PV module with one cell partially shaded in the range of 25 and $75 \%$ on the same by-pass diode's influence zone.

(ii) Two PV modules partially shaded on the same by-pass diode's influence zone.

(iii) Partial and total shading in the same PV module in both by-pass diodes' influence zones.

(iv) Combined partial and total shading in two modules in both by-pass diodes' influences zones.

(v) Partial shading in all the PV modules.

Several parameters can be identified by columns: measurement conditions; shading percentage on each by-pass diode's influence zone (D1 or D2) of each PV module ' $\mathrm{M}_{\mathrm{i}}$ ', which is associated with its respective number of 'MPPT ${ }_{i}$ ' converter; the measured electrical parameters of the PV generator curve; the input electrical parameters and the improvement factor $F_{\mathrm{I}}$; and the output voltage and conversion ratio of each MPPT converter.

The first case is shown in the first five rows of Table III, where shading on M1 is increased from 0 to $75 \%$ on the by-pass diode's zone 1, 'D1'. The Fist row is the case where no shading occurs, and the power benefit only depends on the mismatch between modules. The mismatch between modules in the system analysed is $3 \% . F_{\mathrm{I}}$ values up to $11 \%$ are reached at $40 \%$ shading, and $M_{\mathrm{R}}(D)_{\mathrm{MN}}$ (equal to one) is reached at $60 \%$ shading.

In the following five rows, the second case is shown: PV modules M1 and M2 are partially shaded. An improvement factor $F_{Y}$ of $24 \%$ is obtained, at $40 \%$ and $50 \%$ shading over one cell, on the D1 and D2 zones respectively. $M_{\mathrm{R}}(D)_{\mathrm{MAX}}$ (equal to 2.5 ) is reached at $70 \%$ of shading.

In the third case, $F_{\mathrm{I}}$ values of $21 \%$ and $16 \%$ are obtained, at $40 \%$ and $50 \%$ shading over one cell in one of the diodes' influence zone, having the second zone a totally covered cell.

The fourth case combines partial and total shading in both by-pass diodes' influence zones, in modules M1 and M2. For this case, some of the highest improvement factors of the entire test are reached, at around $18 \%, 28 \%$ and $30 \%$.

In the final case, partial shading on all of the PV modules is tested. Two measurements were taken: small at around $25 \%$ and medium shading at around $40 \%$. In the first one, an $F_{\mathrm{I}}$ value of $10 \%$ was reached, and in the second one, $20 \%$.

According to this analysis, the following main conclusions, in terms of the improvement factor, from the use of MPPT converters are drawn:

(i) Up to $15 \% F_{\mathrm{I}}$ is reached when one solar cell is covered by shadow or dirt in the range of $25 \%$ to $60 \%$, and it is applied in several by-pass diode zones.

(ii) Between $20 \%$ and $30 \%$ (maximum value reached in these tests) $F_{I}$ is reached when each one out of several PV modules is shaded, totally and partially, in the range of $35 \%$ to $60 \%$.

(iii) $\mathrm{Up}$ to $3 \% F_{\mathrm{I}}$ is reached in other cases, especially associated with the reduction of the mismatch effect of the PV modules.

Clear power improvement factors have been observed for specific situations of partial shading or dirt with areas smaller than the solar cell. This shading profile could correspond to obstacles such as poles or antennas, which shade various modules in the system, without totally shading any cell or module. These results are comparable with those obtained in other publications $[25,26]$, which categorise poles as one of the best mitigated shadows by MPPT converters.

However, to conclude whether the system is profitable or not, further energetic and more complex and economical analysis must be carried out. Some of the commercial firms offering these products claim up to $25 \%$ additional energy harvests; however, this is difficult to imagine considering converter efficiency, non-static shading, shading at non-peak irradiance hours, etc., and more critical views [27] claim that, with a $21 \%$ power increase, which is similar to the ones observed, only a $1 \%$ annual energy gain will be obtained.

Proposed distributed conditioning system is mainly intended to be applied to heterogeneous PV systems, which mainly corresponds to BIPV systems. Most of the losses in buildings correspond to the lack of availability of PV inverters, shadows, and lack of uniformity in the PV modules 


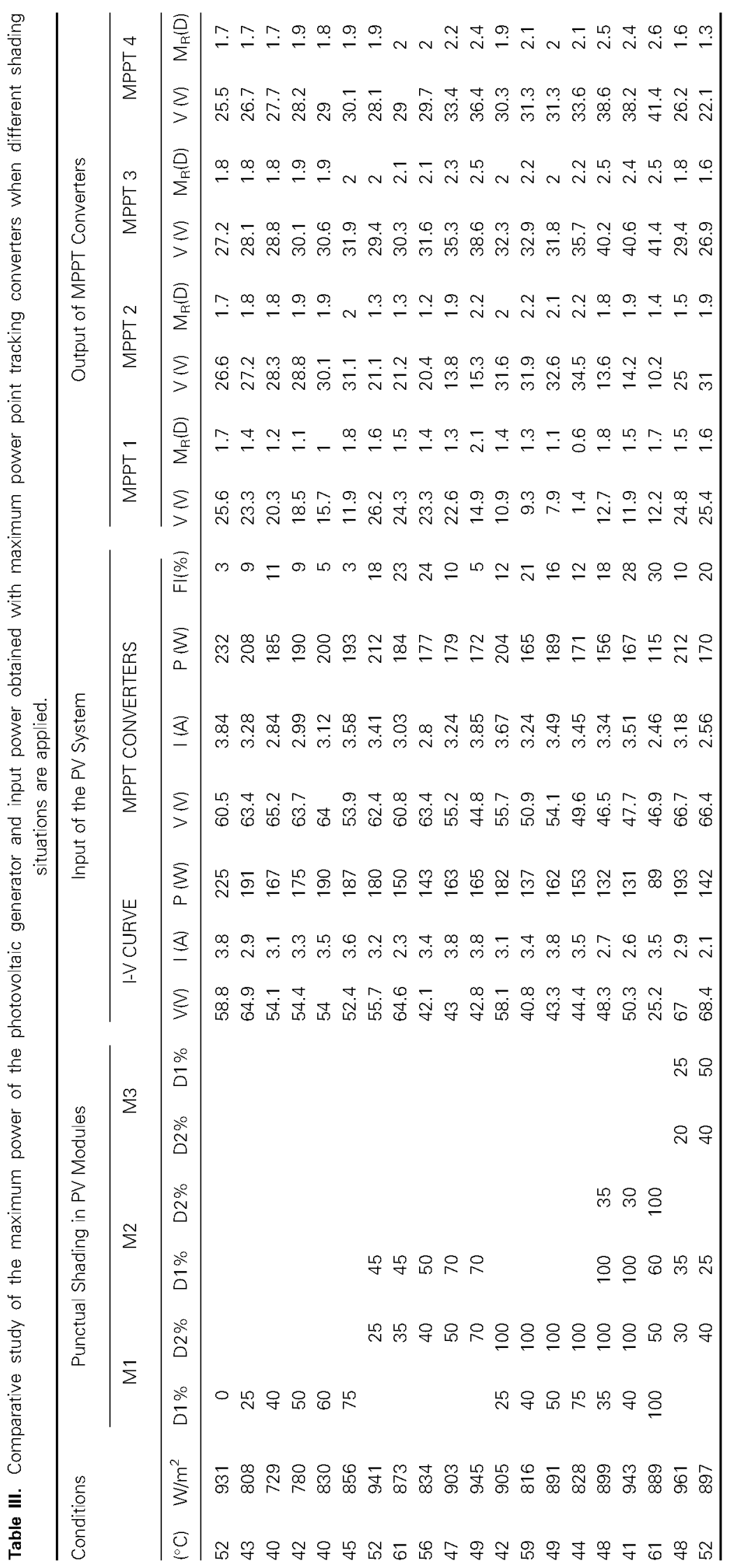


working conditions (differences in temperature between upper and lower modules in a ventilated façade or curtain wall), reflectance from the nearest buildings, different degree of dust depending on the location of the modules, etc.

All of these improvement factors depend greatly on the effect of shading on PV cells and the mismatch between them, which at the same time depends on their reverse characteristics. Simulation models and experimental studies have been conducted $[28,29]$, and these, combined with the analytical models here presented, could serve as the base for a simulation model of the behaviour of PV generators with MPPT converters under shaded conditions.

It is important to note that, the low efficiency of the MPPT converter used in the tests, and all of the improvement factors presented are at the input of the converter; this considered as the ideal improvement factor, $F_{i}$. To obtain the real improvement factor, $F_{i}$ must be multiplied by the converter efficiency, which in the prototype used is approximately $90 \%$. With such a low efficiency, MPPT converters will never be energetically profitable. However, in the market, there are commercial options such as SolarMagic or SolarEdge, with maximum conversion efficiencies of up to $99.5 \%$ [30], this occurring when no shade is present and the converter acting only as a bypass.

\section{CONCLUSIONS}

Distributed architectures are an alternative to central or string inverter-based topologies. The analytical models set out in this paper provide useful information on the behaviour of cascade MPPT converters. A novel characterization method allows to verify on site, and at the same time; the PV module and its MPPT converter associated. In summary, the performance of the MPPT converter strongly depends on three main factors: (1) maximum conversion ratio at maximum decoupling current criteria; (2) by-pass diode effects on the PV module; and (3) input voltage imposed by the grid-connected PV inverter. This last value is necessary to extract the maximum power available in the PV system. The paper also provides a useful tool to simulate numerous PV systems' topologies and environmental conditions.

The progressive shadow profile test provides important information on the tracking of the MPP and the conversion ratio limits. Normally, if shading covers any PV cell over $70 \%$, the decoupled current of the PV module disappears because of the by-pass diodes, and as a consequence, the associated MPPT converter does not provide a power improvement in the PV system. If shading covers more than one PV cell and all the by-pass diode's zones, the decoupling current phenomenon takes place and the MPPT converter fixes the decoupled current in the string. As a consequence, a power improvement factor occurs. Finally, a suitable estimation of the PV inverter voltage protects all MPPT converters from the total decoupling current of any (or more) PV module(s).
Under located shading circumstances, test results have provided important information about the correlation between punctual shading levels and the power improvement factor $F_{\mathrm{I}}$, where the input power of the MPPT converters has been compared with the power available in the PV generator. The main conclusions are as following:

(i) Up to a $15 \% F_{\mathrm{I}}$ is reached when one solar cell is covered by a shadow, dirt, or other object in the range of $25 \%$ to $60 \%$ and applied in several by-pass diode zones.

(ii) An $F_{\text {I }}$ higher than $20 \%$ and less than $30 \%$ (maximum reached in these tests) is reached when, in each one of several PV modules, total and partial shading in the range of $35 \%$ to $60 \%$ are combined.

A power improvement has been reached for specific situations of partial shading or dirt with areas smaller than a solar cell. However, to conclude whether the system is profitable or not, further energetic and more complex economical analysis must be carried out. Apart from the possible energy improvements, other factors should be considered, such as the possible reduction in reliability by adding new components or the added value of a module level monitoring system.

\section{ACKNOWLEDGEMENTS}

This work has been financed by the INTEGRA PV project, which was co-financed by the Spanish Ministry of Industry.

\section{REFERENCES}

1. Uriarte S, Sáenz MJ, Orduz R, Egido MA, Román E, et al. Energy integrated management system for PV applications. Proc. 20th European Photovoltaic Solar Energy Conference, Barcelona, Spain, June 2005; 2.292-2.294.

2. Dunselman CPM, van der Weiden TCJ, de Haan SWH, ter Heide F, van Zoligen RJC. Feasibility and development of PV modules with integrated inverter: AC-modules. Proc. 12th European Photovoltaic Solar Energy Conference, Amsterdam, Netherlands, April 1994; 313-315.

3. Heskes PJM, Rooiji PM, Islam S, Woyte A, Wouters J. Development, production and verification of the second generation of DC-AC modules. PV2GO. Proc. 19th European Photovoltaic Solar Energy Conference, Paris, France, June 2004; 2584-2586.

4. Hempel H, Kleinkauf W, Krengel U. PV-module with integrated power conditioning unit. 11th European Photovoltaic Solar Energy Conference, Montreaux, Switzerland, October 1992; 1080-1083.

5. Schekulin D, Bleil A, Binder C, Schumm G. Moduleintegrable inverters in the power-range of 100400 
watts. 13th European Photovoltaic Solar Energy Conference, Nice, France, October 1995; 1893-1896.

6. Kleinkauf W, Bishop J, Haas O, Raptis F, Sachau J, Zacharias P. Standardisation of systems technology for PV power supply, modular structures with series produced components. 2nd World Conference and Exhibition of Photovoltaic Solar Energy Conversion, Vienna, Austria, July 1998; 2173-2176.

7. Kusakawa M, Nagayoshi H, Kamisako K, Kurokawa $\mathrm{K}$. A new type of module integrated converter with wide voltage matching ability. 2nd World Conference and Exhibition of Photovoltaic Solar Energy Conversion, Vienna, Austria, July 1998; 2104-2107.

8. PVMIPS. Photovoltaic Module with Integrated Module Conversion and interconnection system. Contract No. TREN/04/FP6EN/S07.34959/503123

9. Bower W. Inverters - critical photovoltaic balanceof-system components: status, issues, and newmillennium opportunities. Progress in Photovoltaics: Research and Applications 2000; 8: 113-126.

10. Wilk H, Panhuber C. Power conditioners for grid interactive PV systems, what is the optimal size: $50 \mathrm{~W}$ or $500 \mathrm{~kW}$ ? 13th European Photovoltaic Solar Energy Conference, Nice, France, Oct. 1995, 1867-1870.

11. Walker GR, Sernia PC. Cascaded DC/DC converter connection of photovoltaic modules. IEEE Transactions on Power Electronics July 2004; 19(4): 1130-1139

12. Enslin JHR, Wolf MS, Snyman DB, Swiegers W. Integrated photovoltaic maximum power point tracking converter. IEEE Transactions On Industrial Electronics Dec. 1997; 44(6): 769-773.

13. Hua C, Lin J, Shen C. Implementation of a DSPcontrolled photovoltaic system with peak power tracking. IEEE Transactions On Industrial Electronics Feb. 1998; 45(1): 210-218.

14. Koutroulis E, Koutroulis K, Voulgoris NC. Development of a microcontroler-based, photovoltaic maximum power point tracking control system. IEEE Transactions on Power Electronics Jan. 2001; 16(1): 46-51.

15. Tse KK, Ho BMT, Shu-Hung Chung H, Ron Hui SY. A comparative study of maximum-power-point trackers for photovoltaic panels using switching-frequency modulation scheme. IEEE Transactions On Industrial Electronics April 2004; 51(2): 410-418.

16. Román E, Alonso R, Elorduizapatarietxe S, Ibáñez P. Economic analysis of modular PV systems for building integration. Proc. of the 21st European Photovoltaic Solar Energy Conference and Exhibition, Dresden Germany, Sept. 2006; 2.700-2.703.

17. Podewils C. Treasure in the cellar. Photon International, May 2011; 190.
18. Orduz R. Contribución a los sistemas de control de potencia micro-distribuida en edificios fotovoltaicos. Universidad Politecnica de Madrid. P.h.D. Thesis, 2009; 77-172.

19. Orduz R, Egido MA. Evaluation test results of a new distributed MPPT converter. Proceedings of the 22nd European PV Solar Energy Conference and Exhibition, Milan, Italy, 2006.

20. Román E, Martinez V, Jimeno JC, Alonso R, Elorduizapatarietxe S, Ibáñez P. Experimental results of intelligent PV module for grid-connected PV systems. Solar Energy2008; 82(5): 471-480.

21. Lícia NA, Braz CF, Selenio RS. Control integrated maximum power point tracking methods. Proc. 16th European Photovoltaic Solar Energy Conference, Glasgow, UK, May 2000; 2582-2585

22. Hohm DP, Ropp ME. Comparative study of maximum power point tracking algorithms. Progress in Photovoltaics: Research and Applications Apr. 2003; 11 : 47-62.

23. Jantsch M, Real M, Häberlin H, Whitaker C, Kurokawa K, Blässer G, Kremer P, Verhoeve C. Measurement of PV maximum power point tracking performance. Proc. of the 14th European Photovoltaic Solar Energy Conference, Barcelona Spain, May 1997; 2188-2193.

24. Sanchis P, López J, Ursúa A, Gubía E, Marroyo L. On the testing, characterization, and evaluation of PV inverters and dynamic MPPT performance under real varying operating conditions. Progress in Photovoltaics 2007; 15: 541-556.

25. Orduz R, Camaño-Martín E. Quality assurance in PV rural electrification programs: characterization method for crystalline silicon PV module. Proc. of the 19th European Photovoltaic Solar Energy Conference, Paris, France, 2004; 2622-2625.

26. Solórzano J, Egido MA, Orduz R. Power optimisation in PV generators using MPPT modules. Proc. of the 25th European Photovoltaic Solar Energy Conference, Valencia, Spain, 2010; 4595-4600.

27. Rogalla S, Burger B, Goeldi B, Schmidt H. Light and shadow-When is MPP-tracking at the module level worthwhile?. Proc. of the 25th European Photovoltaic Solar Energy Conference, Valencia, Spain, 2010; 3932-3936.

28. Silvestre S, Chouder A. Effects of shadowing on photovoltaic module performance. Progress in Photovoltaics 2008; 16: 141-149.

29. Alonso García MC, Ruiz JM, Chenlo F. Experimental study of mismatch and shading effects in the I-V characteristics of a photovoltaic module. Solar Energy Materials \& Solar Cells 2006; 90: 329-340.

30. Podewils C, Levitin M. Hidden powers. Photon International February 2011; 136-147. 